\title{
An improved procedure for the preparation of chiral nonracemic $N$-tosyl-2-alkylaziridines and $N, 2$-dialkylaziridines on multigram-scale
}

\author{
Jose L.Vicario, Dolores Badía, *and Luisa Carrillo \\ Departamento de Química Orgánica II. Facultad de Ciencia y Tecnología. Universidad del País \\ Vasco/Euskal Herriko Unibertsitatea. P.O. Box 644, E-48080, Bilbao, Spain \\ E-mail: dolores.badia@ehu.es
}

Dedicated to Prof. Joan Bosch on his $60^{\text {th }}$ birthday

\begin{abstract}
A modified and improved procedure has been developed for the preparation of chiral nonracemic $N$-tosyl-2-alkyl aziridines in a single step starting from readily available $\beta$-amino alcohols. The procedure relies on a one pot $N$-tosylation/O-tosylation/intramolecular $\mathrm{S}_{\mathrm{N}}$ displacement, which furnishes the target heterocycles in excellent yields. The application of this protocol on a multigram scale has also been explored with excellent results. In addition, the application of a similar methodology has also allowed the preparation of $N$-benzyl-2-alkyl aziridines.
\end{abstract}

Keywords: Aziridines, $\beta$-amino alcohols

\section{Introduction}

Chiral aziridines have shown to be extremely interesting and useful compounds in organic synthesis, ${ }^{1}$ due to their known ability to undergo highly regio- and diastereoselective ringopening reactions with a wide variety of nucleophiles. ${ }^{2}$ In addition, they have also been employed as sources of chirality in stereocontrolled reactions and some examples of their use as chiral auxiliaries or ligands in asymmetric synthesis can be found in the literature. ${ }^{3}$ For these reasons, many methods have been developed for the asymmetric synthesis of such important chiral intermediates, most of them focused on transformation of substrates from the chiral pool, like $\alpha$-amino acids or derivatives. ${ }^{4}$

Very recently we have reported a very efficient stereoselective ring-opening reaction of aziridines with chiral enolates under double stereodifferentiation conditions, which allowed us to obtain $\alpha$-methyl- $\gamma$-amino amide derivatives in a highly stereoselective way (scheme 1$){ }^{5}$ During our studies, we found that the presence of an electron withdrawing group such as a para- 
toluenesulfonyl group at the aziridine nitrogen atom which stabilizes the developing negative charge during the reaction was crucial for the ring-opening reaction to occur. After identifying the matched and mismatched combination of reagents, we found that the ring opening reaction proceeded in excellent yields and diastereoselectivities in all cases tested and the obtained adducts could be successfully converted into enantiomerically pure $\alpha$-methyl- $\gamma$-amino acids and esters and the latter could be easily transformed into the corresponding $\gamma$-lactams, showing the high potential of this methodology in asymmetric synthesis.

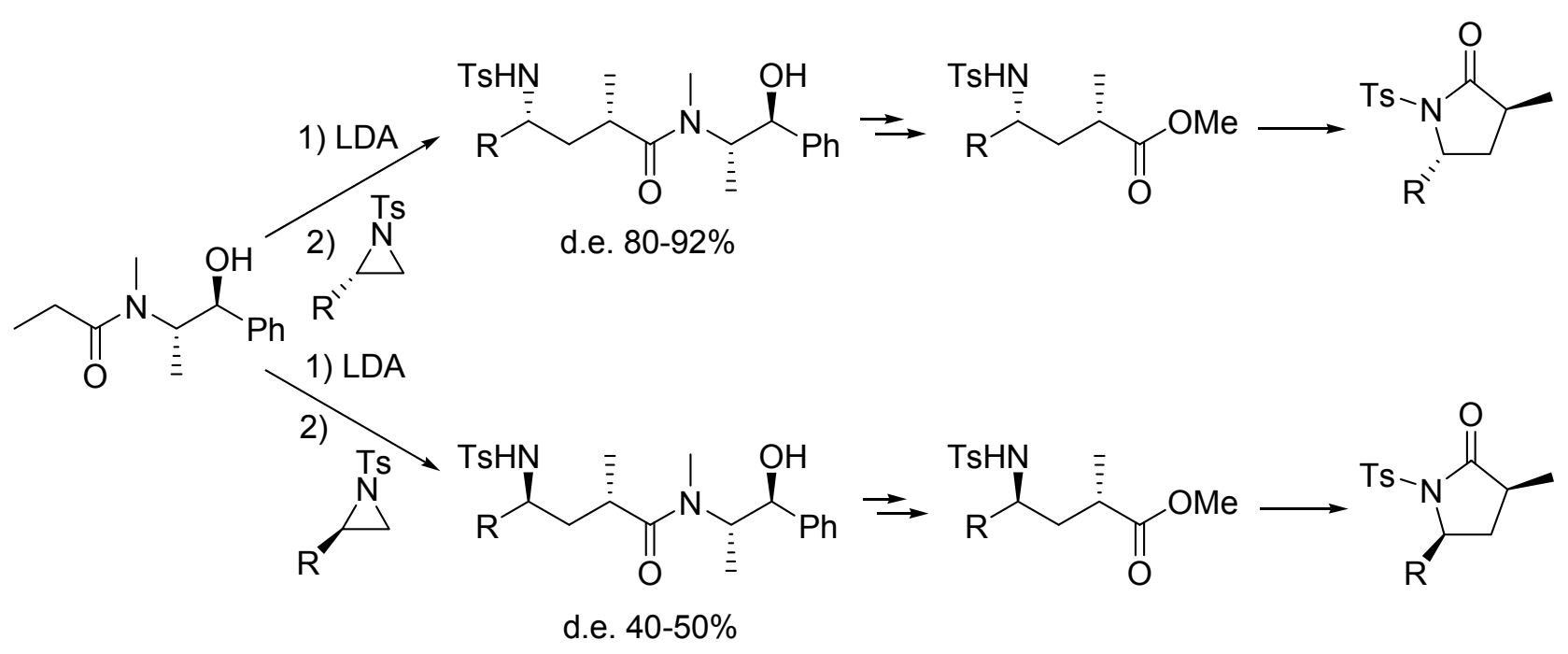

\section{Scheme 1}

In this context, and in connection with these studies, we needed a simple protocol for the preparation of chiral nonracemic aziridines in multigram quantities. Related to this topic, most of the methods reported in the literature for the preparation of chiral 2-alkyl aziridines suffer from important drawbacks, especially related to the low yields generally obtained when performing the described transformations on large scale, mainly due to the number of steps required or to problems found during the work-up procedure or during the purification of the final or intermediate products. For that reason, we decided to develop an improved protocol for the preparation of chiral $\mathrm{N}$-tosyl 2-alkyl aziridines in multigram quantities, which we wish to preset in this paper. This procedure consists of the transformation of commercially available enantiopure $\beta$-amino alcohols into the target aziridines in a single step.

\section{Results and Discussion}

We started our study based on conditions reported in a previous paper in which $N$-tosyl $\beta$-amino alcohols were successfully transformed into the corresponding aziridines by $O$-tosylation/basepromoted cyclization. ${ }^{6}$ The substrates needed for this transformation had to be prepared in a two 
step sequence by $N$-tosylation of the corresponding $\alpha$-amino acid followed by reduction. With this precedent in mind, we thought that the $N$-tosylation and cyclization could also be performed in a single operation starting from the analogous $N$-unprotected $\beta$-amino alcohol and therefore we proceeded to react $100 \mathrm{mg}$ of $(S)$-alaninol with 2.5 eq. of tosyl chloride and excess (3.0 eq.) triethylamine in $\mathrm{CH}_{2} \mathrm{Cl}_{2}$ and in the presence of a catalytic amount of DMAP, observing that the expected $\mathrm{N}$-tosyl-2-methyl aziridine was formed in a clean way after $24 \mathrm{~h}$. When we applied these conditions to higher amounts of the starting substrate $(1 \mathrm{~g}$ or $10 \mathrm{~g}$ ) the reaction showed to be equally effective, giving comparable yields of the final compound. Other differently substituted $\beta$-amino alcohols were subjected to these conditions.

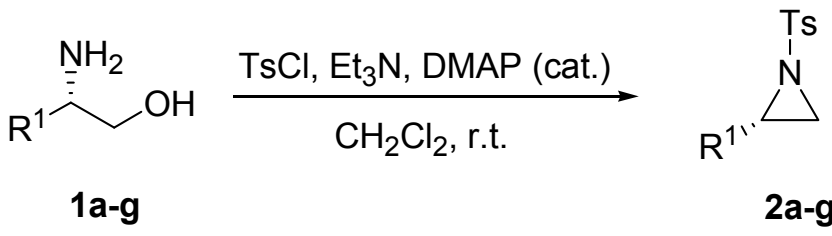

\section{Scheme 2}

Table 1. Synthesis of $N$-tosyl aziridines $\mathbf{2 a - g}$ from $\beta$-amino alcohols 1a-g

\begin{tabular}{ccccccc}
\hline Entry $^{a}$ & Prod. & $\mathrm{R}^{1}$ & Yield $^{b}$ & {$[\alpha]_{\mathrm{D}}^{20}$} & Lit. $[\alpha]_{\mathrm{D}}{ }^{20}$ & Ref. \\
\hline 1 & $\mathbf{2 a}$ & $\mathrm{Me}$ & 89 & $+33.1\left(c=0.3, \mathrm{CH}_{2} \mathrm{Cl}_{2}\right)$ & $+32.1\left(c=1.0, \mathrm{CH}_{2} \mathrm{Cl}_{2}\right)$ & 6 \\
2 & $\mathbf{2 b}$ & $\mathrm{Et}$ & 93 & $+13.1\left(c=1.0, \mathrm{CH}_{2} \mathrm{Cl}_{2}\right)$ & $+11.0\left(c=1.4, \mathrm{CHCl}_{3}\right)$ & 7 \\
3 & $\mathbf{2 c}$ & $i-\mathrm{Pr}$ & 86 & $+14.8\left(c=0.5, \mathrm{CH}_{2} \mathrm{Cl}_{2}\right)$ & $+14.8\left(c=1.0, \mathrm{CH}_{2} \mathrm{Cl}_{2}\right)$ & 6 \\
4 & $\mathbf{2 d}$ & $\mathrm{Ph}$ & 93 & $+51.5\left(c=0.3, \mathrm{CH}_{2} \mathrm{Cl}_{2}\right)$ & $+65.5\left(c=1.0, \mathrm{C}_{6} \mathrm{H}_{6}\right)$ & 8 \\
5 & $\mathbf{2 e}$ & $\mathrm{CH}_{2} \mathrm{Ph}$ & 91 & $+10.7\left(c=0.3, \mathrm{CH}_{2} \mathrm{Cl}_{2}\right)$ & $+10.1\left(c=1.0, \mathrm{CH}_{2} \mathrm{Cl}_{2}\right)$ & 6 \\
6 & $\mathbf{2 f}$ & $\mathrm{CH}_{2}=\mathrm{CHCH}_{2}$ & 90 & $+20.1\left(c=0.3, \mathrm{CH}_{2} \mathrm{Cl}_{2}\right)$ & $+18.9(c=4.3, \mathrm{AcOEt})$ & 9 \\
7 & $\mathbf{2 g}$ & $\mathrm{CH}_{2}=\mathrm{CHCH}_{2} \mathrm{CH}_{2}$ & 88 & $+27.5\left(c=0.3, \mathrm{CH}_{2} \mathrm{Cl}_{2}\right)$ & $+27.8(c=3.6, \mathrm{AcOEt})$ & 9 \\
\hline
\end{tabular}

${ }^{a}$ All reactions were run on a $10.0 \mathrm{~g}$. scale

${ }^{b}$ Yield of pure compound after flash column chromatography purification.

As it is shown in table 1, the employed protocol furnished the corresponding aziridines in excellent yields in all cases tested, showing that these were consistently high regardless of the nature of the $\mathrm{R}^{1}$ substituent at the chiral $\beta$-amino alcohol substrate. All the analytical and spectroscopic data of the prepared aziridines $\mathbf{2 a - g}$ matched with those reported in the literature. In particular, the fact that the $[\alpha]_{\mathrm{D}}{ }^{20}$ values obtained by us for the aziridines prepared were in good agreement with those reported, allowed us to conclude that the stereochemical integrity of the center of chirality present at the starting materials had been maintained during the $N$ tosylation/cyclization process. It is important to point out that the reaction was performed in all cases on a $10 \mathrm{~g}$. scale, which allowed us to prepare high quantities of the target aziridines in a single step and using a very simple protocol. 
The advantages of this procedure compared to the original methodology reported by Berry and Craig, ${ }^{6}$ are mainly those derived from the lower number of steps employed in our case. If we consider that $\beta$-amino alcohols are normally prepared from the corresponding $\alpha$-amino acids, our procedure consists of two synthetic steps, starting from the same kind of substrate, while the aforementioned procedure needs an additional step consisting of the $N$-tosylation of the starting $\alpha$-amino acids. Moreover, if we take into account that most chiral $\beta$-amino alcohols are usually commercially available, the target aziridines could be obtained by us in a single step using this very simple protocol.

We have also tested the synthesis of other $N$-substituted aziridines employing this methodology. For this purpose we first had to convert starting $\beta$-amino alcohols into the corresponding $N$-alkyl derivatives $\mathbf{3 a - g}$ by condensation with the corresponding aldehyde followed by in situ reduction of the obtained oxazolidine. These $N$-alkyl $\beta$-amino alcohols furnished cleanly the expected aziridines 4a-g upon treatment with tosyl chloride and triethylamine in the presence of catalytic amounts of DMAP (scheme 3 ).

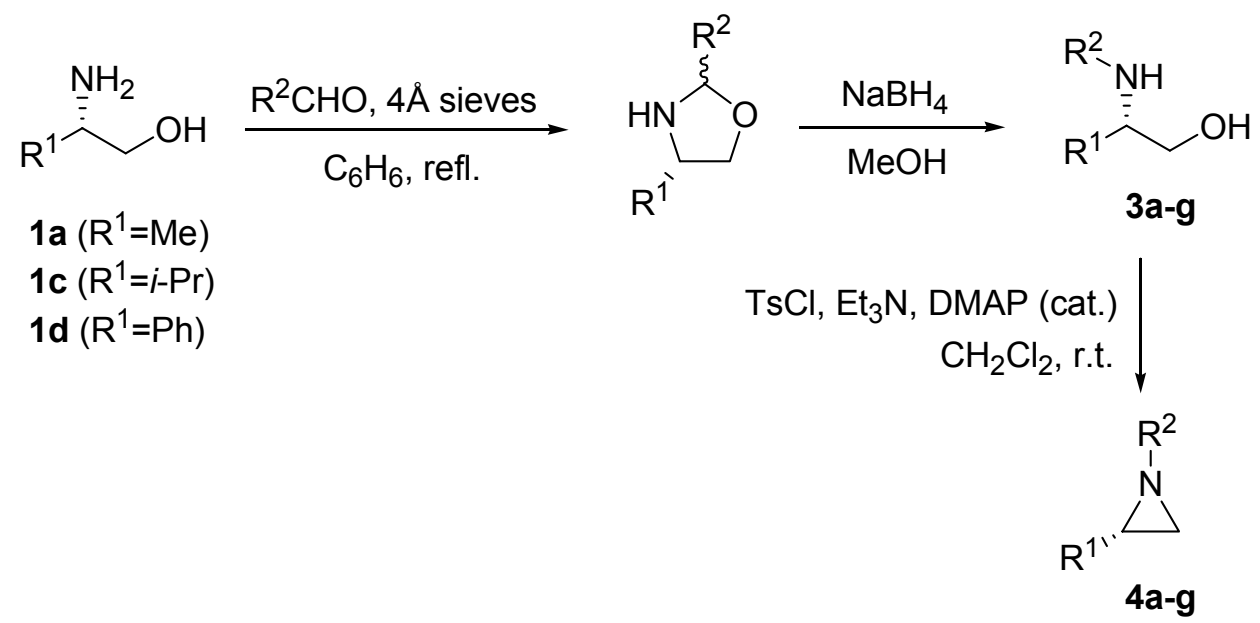

\section{Scheme 3}

Table 2. Synthesis of $N$-Alkyl aziridines 4a-g from $\beta$-amino alcohols $\mathbf{1 a}, \mathbf{1 c}$ and $\mathbf{1 d}$

\begin{tabular}{ccccccc}
\hline Entry $^{a}$ & $\mathrm{R}^{1}$ & $\mathrm{R}^{2}$ & Prod. & Yield $^{b}$ & Prod. & Yield $^{b}$ \\
\hline 2 & $\mathrm{Ph}$ & $\mathrm{Me}$ & $\mathbf{3 a}$ & 95 & $\mathbf{4 a}$ & 85 \\
3 & $\mathrm{Ph}$ & $\mathrm{CH}_{2} \mathrm{CH}=\mathrm{CH}_{2}$ & $\mathbf{3 b}$ & 92 & $\mathbf{4 b}$ & 86 \\
4 & $\mathrm{Ph}$ & $i-\mathrm{Pr}$ & $\mathbf{3 c}$ & 94 & $\mathbf{4 c}$ & 82 \\
5 & $\mathrm{Ph}$ & $n-\mathrm{Bu}$ & $\mathbf{3 d}$ & 90 & $\mathbf{4 d}$ & 87 \\
1 & $\mathrm{Ph}$ & $\mathrm{CH}_{2} \mathrm{Ph}$ & $\mathbf{3 e}$ & 88 & $\mathbf{4 e}$ & 90 \\
6 & $\mathrm{Me}$ & $\mathrm{CH}_{2} \mathrm{Ph}$ & $\mathbf{3 f}$ & 92 & $\mathbf{4 f}$ & 87 \\
7 & $i-\mathrm{Pr}$ & $\mathrm{CH}_{2} \mathrm{Ph}$ & $\mathbf{3 g}$ & 90 & $\mathbf{4 g}$ & 91 \\
\hline
\end{tabular}

${ }^{a}$ All reactions were run at 1.0 g. scale

${ }^{b}$ Yield of pure compound after flash column chromatography purification. 
In conclusion, we have set up a very efficient and simple procedure for the preparation of chiral nonracemic $N$-tosyl 2-alkyl aziridines in a single step starting from the corresponding chiral $\beta$-amino alcohols. The designed protocol involves a sequential one-pot $N$-tosylation/Otosylation and a final intramolecular nucleophilic substitution step, which delivers the target heterocycles in excellent yields. The same procedure can also be applied for the preparation of other $\mathrm{N}$-alkyl substituted aziridines, although in this case performing first an $\mathrm{N}$-alkylation procedure prior to the cyclization step.

\section{Experimental Section}

General Procedures. Melting points were determined in unsealed capillary tubes and are uncorrected. IR spectra were obtained on $\mathrm{KBr}$ pellets (solids) or $\mathrm{CHCl}_{3}$ solution (oils). NMR spectra were recorded at $20-25^{\circ} \mathrm{C}$, running at $250 \mathrm{MHz}$ for ${ }^{1} \mathrm{H}$ and $62.8 \mathrm{MHz}$ for ${ }^{13} \mathrm{C}$ in $\mathrm{CDCl}_{3}$ solution and resonances are reported in ppm relative to tetramethylsilane unless otherwise stated. Mass spectra were recorded under electron impact at $70 \mathrm{eV}$. TLC was carried out with $0.2 \mathrm{~mm}$. thick silica gel plates (Merck Kiesegel $\mathrm{GF}_{254}$ ) and visualization was accomplished by UV light or by spraying with phosphomolybdic acid. Flash column chromatography on silica gel was performed with Merck Kiesegel 60 (230-400 mesh). All solvents used in reactions were dried and purified according to standard procedures. All air- or moisture-sensitive reactions were performed under argon. The glassware was oven dried $\left(140^{\circ} \mathrm{C}\right)$ overnight and purged with argon prior to use.

\section{General procedure for the one-pot synthesis of $\boldsymbol{N}$-Tosyl-2-alkylaziridines $2 \mathrm{a}-\mathrm{g}$}

$\mathrm{Et}_{3} \mathrm{~N}(0.30 \mathrm{~mol})$ was added to a cooled $\left(0^{\circ} \mathrm{C}\right)$ solution of the starting $\beta$-amino alcohol 1a-g $(0.1$ $\mathrm{mol}), \mathrm{TsCl}(0.25 \mathrm{~mol})$ and DMAP $(20 \mathrm{mg})$ in dry $\mathrm{CH}_{2} \mathrm{Cl}_{2}(400 \mathrm{~mL})$. The mixture was allowed to reach to r.t. and stirred at this temperature for $24 \mathrm{~h}$, after which a saturated $\mathrm{NH}_{4} \mathrm{Cl}$ solution $(200$ $\mathrm{mL})$ was added. The mixture was extracted with $\mathrm{CH}_{2} \mathrm{Cl}_{2}(3 \times 70 \mathrm{~mL})$ and the organic fractions were collected, dried over $\mathrm{Na}_{2} \mathrm{SO}_{4}$, filtered and the solvent removed in vacuo affording the desired aziridines 2a-f after flash column chromatography purification (hexanes/AcOEt 8:2).

(2S)-(+)- $N$-(p-toluenesulfonyl)-2-methylaziridine (2a). The reaction of $(S)-(+)$-alaninol $(10.00$ $\mathrm{g}, 0.13 \mathrm{~mol}), \mathrm{TsCl}(50.45 \mathrm{~g}, 0.27 \mathrm{~mol})$, DMAP (30 mg) and $\mathrm{Et}_{3} \mathrm{~N}$ (50.7 mL, $0.40 \mathrm{~mol}$ ) following the general procedure furnished aziridine $\mathbf{2 a}(25.0 \mathrm{~g}, 0.11 \mathrm{~mol})$ after flash column chromatography purification. Yield: $89 \%$. Mp. 56-58 ${ }^{\circ} \mathrm{C}\left(\mathrm{Et}_{2} \mathrm{O}\right.$ :Hexanes 1:1), (Lit. ${ }^{6}$ 58-59 $\left.{ }^{\circ} \mathrm{C}\right)$. $[\alpha]_{\mathrm{D}}{ }^{20}:+33.1\left(\mathrm{c}=0.3, \mathrm{CH}_{2} \mathrm{Cl}_{2}\right)$. (Lit. $\left.{ }^{6}+32.1 \mathrm{c}=1.0, \mathrm{CH}_{2} \mathrm{Cl}_{2}\right)$. IR $(\mathrm{KBr}): 1340,1150\left(\mathrm{SO}_{2}\right) .{ }^{1} \mathrm{H}-$ $\operatorname{NMR}(\delta, \mathrm{ppm}): 1.15(\mathrm{~d}, 3 \mathrm{H}, J=5.6 \mathrm{~Hz}) ; 1.93(\mathrm{~d}, 1 \mathrm{H}, J=4.6 \mathrm{~Hz}) ; 2.34(\mathrm{~s}, 3 \mathrm{H}) ; 2.50(\mathrm{~d}, 1 \mathrm{H}, J=7.0$ $\mathrm{Hz}) ; 2.72(\mathrm{~m}, 1 \mathrm{H}) ; 7.24(\mathrm{~d}, 2 \mathrm{H}, J=8.0 \mathrm{~Hz}) ; 7.73$ (d, 2H, $J=8.0 \mathrm{~Hz}) .{ }^{13} \mathrm{C}-\mathrm{NMR}(\delta, \mathrm{ppm}): 16.4$; 21.2; 34.3; 35.5; 127.4, 129.4; 134.8; 144.1. MS (EI) $m / z$ (Rel. Int.): 155 (1), 139 (1), 105 (2), 91 (13), 65 (12), 56 (100), 51 (2). 
The other aziridines were prepared according to the general procedure. Analytical and spectroscopic data for $\mathbf{2} \mathbf{b},{ }^{7} \mathbf{2 c},{ }^{6} \mathbf{2} \mathbf{d},{ }^{8} \mathbf{2} \mathbf{e},{ }^{6} \mathbf{2} \mathbf{f}^{9}$ and $\mathbf{2 g}^{9}$ matched with those reported in the literature:

\section{General procedure for the $\boldsymbol{N}$-alkylation of $\beta$-amino alcohols}

A suspension of the corresponding $\beta$-amino alcohol 1a, 1c or 1d (10mmol) and the corresponding aldehyde $(10 \mathrm{mmol})$ in $80 \mathrm{~mL}$ of benzene was refluxed for $12 \mathrm{~h}$. in the presence of powdered $4 \AA$ mol. sieves $(5 \mathrm{~g})$. Then, the mixture was cooled to r.t., filtered and the solvent was removed in vacuo. The resulting yellowish oil was next dissolved in $\mathrm{MeOH}(50 \mathrm{~mL})$ and $\mathrm{NaBH}_{4}$ (20mmol) was added in three portions. The mixture was stirred until TLC indicated full conversion (typically $12 \mathrm{~h})$ and sat. $\mathrm{NH}_{4} \mathrm{Cl}(100 \mathrm{~mL})$ was added. The mixture was extracted with $\mathrm{CH}_{2} \mathrm{Cl}_{2}(3 \mathrm{x} 80 \mathrm{~mL})$ and the combined organic fractions were collected, dried over $\mathrm{Na}_{2} \mathrm{SO}_{4}$, filtered and the solvent was removed in vacuo to afford the target $N$-alkyl $\beta$-amino alcohol 3a-g after flash column chromatography purification (hexanes/ethyl acetate 3:7).

(2S)-(+)-2-amino- $\boldsymbol{N}$-benzyl-2-phenylethanol (3e). The reaction of $(S)-(+)$-phenylglycinol (1.00 g, $7.30 \mathrm{mmol})$, benzaldehyde $(0.77 \mathrm{~g}, 7.30 \mathrm{mmol})$, and $\mathrm{NaBH}_{4}(0.55 \mathrm{~g}, 14.60 \mathrm{mmol})$ following the general procedure furnished $N$-benzyl $\beta$-amino alcohol 3e (1.46 g, $6.42 \mathrm{mmol})$ after flash

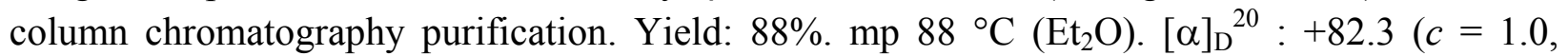
$\left.\mathrm{CHCl}_{3}\right)$. (Lit. ${ }^{10}-82.5, c=1.0, \mathrm{CHCl}_{3}$ for the $R$ isomer). IR (KBr): $3445(\mathrm{NH}+\mathrm{OH}) .{ }^{1} \mathrm{H}-\mathrm{NMR}(\delta$, ppm): 2.75 (bs, 2H); 3.53 (dd, $1 \mathrm{H}, J=8.7,11.0 \mathrm{~Hz}), 3.55$ (d, 1H, $J=13.0 \mathrm{~Hz}), 3.66$ (dd, $1 \mathrm{H}, J=$ $4.2,11.0 \mathrm{~Hz}), 3.70(\mathrm{~d}, 1 \mathrm{H}, J=13.0 \mathrm{~Hz}), 3.80(\mathrm{dd}, 1 \mathrm{H}, J=4.2,8.7 \mathrm{~Hz}), 7.45-7.20(\mathrm{~m}, 10 \mathrm{H}),{ }^{13} \mathrm{C}-$ NMR $(\delta, \mathrm{ppm}): 51.2 ; 63.9,66.8,128.5 ; 128.7 ; 129.0 ; 129.2 ; 129.6 ; 127.1,140.0,140.5$.

The other $N$-alkyl $\beta$-amino alcohols were prepared according to the general procedure. Analytical and spectroscopic data for $\mathbf{3 a},{ }^{11} \mathbf{3 b},{ }^{12} \mathbf{3 c},{ }^{13} \mathbf{3 d},{ }^{14} \mathbf{3} \mathbf{f}^{15}$ and $\mathbf{3} \mathbf{g}^{16}$ matched with those reported in the literature.

\section{General procedure for the synthesis of aziridines $\mathbf{4 a - g}$}

$\mathrm{Et}_{3} \mathrm{~N}(1.5 \mathrm{mmol})$ was added over a cooled $\left(0^{\circ} \mathrm{C}\right)$ solution of the starting $N$-alkyl $\beta$-amino alcohol 1a-d $(1.0 \mathrm{mmol}), \mathrm{TsCl}(1.2 \mathrm{mmol})$ and DMAP $(5 \mathrm{mg})$ in dry $\mathrm{CH}_{2} \mathrm{Cl}_{2}(100 \mathrm{~mL})$. The mixture was allowed to reach r.t. and stirred at this temperature for $24 \mathrm{~h}$., after which a saturated $\mathrm{NH}_{4} \mathrm{Cl}$ solution $(50 \mathrm{~mL})$ was added. The mixture was extracted with $\mathrm{CH}_{2} \mathrm{Cl}_{2}(3 \times 30 \mathrm{~mL})$ and the organic fractions were collected, dried over $\mathrm{Na}_{2} \mathrm{SO}_{4}$, filtered and the solvent removed in vacuo affording the wanted aziridines 4a-g after flash column chromatography purification (hexanes/AcOEt 8:2).

(2S)-(+)- $N$-(Benzyl)-2-phenylaziridine (4e). The reaction of $(S)-(+)-N$-benzylphenylglycinol 3e (1.00 g, $4.40 \mathrm{mmol}), \mathrm{TsCl}(1.00 \mathrm{~g}, 5.29 \mathrm{mmol}), \mathrm{DMAP}(10 \mathrm{mg})$ and $\mathrm{Et}_{3} \mathrm{~N}(0.92 \mathrm{~mL}, 6.60 \mathrm{mmol})$ following the general procedure furnished aziridine $4 \mathrm{e}(0.83 \mathrm{~g}, 3.96 \mathrm{mmol})$ after flash column chromatography purification. Yield: $90 \% \cdot[\alpha]_{\mathrm{D}}{ }^{20}:+50.1\left(\mathrm{c}=1.0, \mathrm{CH}_{2} \mathrm{Cl}_{2}\right)$. $\left(\right.$ Lit. $^{17}+49.0 c=2.0$, EtOH);). ${ }^{1} \mathrm{H}-\mathrm{NMR}(\delta, \mathrm{ppm}): 1.84(\mathrm{~d}, 3 \mathrm{H}, J=6.6 \mathrm{~Hz}), 1.98(\mathrm{~d}, 1 \mathrm{H}, J=3.2 \mathrm{~Hz}), 2.50(\mathrm{dd}, 1 \mathrm{H}, J=$ 
3.2, $6.6 \mathrm{~Hz}), 3.58(\mathrm{~d}, 1 \mathrm{H}, J=13.8 \mathrm{~Hz}), 3.69(\mathrm{~d}, 1 \mathrm{H}, J=13.8 \mathrm{~Hz}), 7.18-7.42(\mathrm{~m}, 10 \mathrm{H}) .{ }^{13} \mathrm{C}-\mathrm{NMR}$ $(\delta, \mathrm{ppm}): 38.3 ; 41.9 ; 65.1 ; 126.7 ; 127.6 ; 128.2 ; 128.7 ; 129.8 ; 139.2 ; 140.5 ; 145.4$.

The other aziridines 4 were prepared according to the general procedure. Analytical and spectroscopic data $\mathbf{4 a},{ }^{18} \mathbf{4 b},{ }^{19} \mathbf{4} \mathbf{c},{ }^{19} \mathbf{4} \mathbf{d},{ }^{20} \mathbf{4 f}^{21}$ and $\mathbf{4 g}^{22}$ matched with those reported in the literature.

\section{Acknowledgements}

The authors thank the University of the Basque Country (Subvención General a Grupos de Investigación, 9/UPV00041.310-15835/2004) and the Spanish Ministerio de Educación y Ciencia (CTQ2005-02131/BQU) for financial support. The authors also acknowledge PETRONOR, S.A. (Muskiz, Bizkaia) for the generous gift of solvents.

\section{References and Footnotes}

1. For some reviews see: (a) Sweeney, J. B. Chem. Soc. Rev. 2002, 31, 247. (b) McCoul, W. M.; Davis, F. A. Synthesis 2000, 1347. (c) Tanner, D. Angew. Int. Ed. 1994, 33, 599.

2. Review: Hu, X. E. Tetrahedron 2004, 60, 2701.

3. Seyden-Penne, J. Chiral Auxiliaries and Ligands in Asymmetric Synthesis; John Wiley and Sons: New York, 1995, Chapter 6.8, p 306.

4. For a review see Osborn, H. M. I.; Sweeney, J. Tetrahedron: Asymmetry 1997, 8, 1693. See also refs. 1 and 2.

5. Vicario, J. L; Badía; D.; Carrillo, L. J. Org. Chem. 2001, 66, 5801.

6. Berry, M. B.; Craig, D. Synlett 1992, 41.

7. Compain, P.; Goro, J.; Vatele, J. M. Tetrahedron 1996, 52, 10405.

8. Davis, F. A.; Zhou, P.; Liang, C.-H.; Reddy, R. E. Tetrahedron: Asymmetry 1995, 6, 1511.

9. Lapinsky, D. J.; Bergmeier, S. C. Tetrahedron 2002, 58, 7109.

10. Maury, C.; Gharbaoui, T.; Royer, J.; Husson, H.-P. J. Org. Chem. 1996, 96, 3687.

11. Huszthy, P.; Oue, M.; Bradshaw, J. S.; Zhu, C. Y.; Wang, T.; Dalley, N. K.; Curtis, J. C.; Izatt, R. M. J. Org. Chem. 1992, 57, 5383.

12. Couty, F.; Prim, D. Tetrahedron: Asymmetry 2002, 13, 2619

13. Hirose, K.; Fujiwara, A.; Matsunaga, K.; Aoki, N.; Tobe, Y. Tetrahedron: Asymmetry 2003, $14,555$.

14. Chini, M.; Crotti, P.; Macchia, F. J. Org. Chem. 1991, 56, 5939.

15. Leskovsek, V.; Urleb, U. Synth. Commun. 1994, 24, 1415.

16. Brauner-Osborne, H.; Bunch, L.; Chopin, N.; Couty, F.; Evano, G.; Jensen, A. A.; Kusk, M.; Nielsen, B.; Rabasso, N. Org. Biomol. Chem. 2005, 3, 3996.

17. Kawamoto, A. M. Wills, M. J. Chem. Soc. ; Perkin Trans 1 2001, 1916. 
18. Barsetti, P.; Crist, D. R. J. Heterocyclic Chem. 1975, 12, 1287.

19. Tsuchiya, Y.; Kumamoto, T.; Ishikawa, T. J. Org. Chem. 2004, 69, 8504.

20. Baeg, J.-O.; Bensimon, C.; Alper, H. J. Am. Chem. Soc. 1995, 117, 4700.

21. Katritzky, A. R.; Jiang, J.; Urogdi, L. Synthesis 1990, 565.

22. Piotti, M.; Alper, H. J. Org. Chem. 1996, 118, 111. 